\title{
LA DISPUTA POR EL SENTIDO DE LA TEOLOGÍA POLÍTICA EN LEVIATÁN DE THOMAS HOBBES
}

\author{
Gabriela Rodríguez Rial ${ }^{1}$ \\ Conicet
}

\begin{abstract}
RESUMEN
Este artículo se ocupa del sentido de la teología política en las dos últimas partes de Leviatán, o la materia, forma y poder de un Estado eclesiástico o civil: "De un Estado cristiano" y "El reino de las tinieblas". El análisis de estas secciones del opus magnum hobbesiano se centra en tres temas: la forma política de los reinos de Dios en la tierra, la interpretación "materialista" de los espíritus y la concepción del soberano civil como suprema autoridad interpretativa. A partir de la querella entre Carl Schmitt y Erik Peterson respecto de la legitimidad política y doctrinal de la teología, se identifican presupuestos teóricos y metodológicos que están presentes en la argumentación presentada por Hobbes cuando aborda el vínculo entre religión y política. Si bien se adopta una perspectiva hermenéutica textualista que se restringe a un corpus limitado de la producción de Thomas Hobbes, el objetivo del artículo es reconocer en la teología política una práctica teórico política útil para conceptualizar las formas políticas representativas de una época.
\end{abstract}

Palabras clave: Hobbes; Teología; Política; Representación; Religión; Historia.

\begin{abstract}
This article addresses the meaning of political theology in the two final parts of Thomas Hobbes' Leviathan or The Matter, Forme and Power of a Common-Wealth Ecclesiasticall and Civill, i.e., "Of a Christian Commonwealth" and "Of the Kingdom of Darkness". The study of these sections of the Hobbesian opus magnum focuses on three main topics: the political form of the Kingdoms of God on Earth, the "materialist" interpretation of the spirits and the idea of the civil sovereign as the highest interpretative authority. From the quarrel between Carl Schmitt and Erik Peterson on the political and doctrinal legitimacy of theology, the article identifies the theoretical and methodological premises of Hobbes' argument regarding the relationship between religion and politics and the links between sovereignty and representation. Despite its hermeneutical perspective, which entails the analysis of a limited fraction of Thomas Hobbes's work, the central aim of this article is to acknowledge political theology as a political and theoretical practice particularly useful to conceptualize the political forms representative of a period.
\end{abstract}

Keywords: Hobbes; Theology; Political; Representation; Religion; History.

\footnotetext{
${ }^{1}$ rodriguezgabriela@ conicet.gov.ar
} 


\section{1. ¿QUÉ ES LA TEOLOGÍA POLÍTICA?}

Dico autem alium Articulum fidei praeter hunc, IESUM ESSE CHRISTVM, homini Christiano, vt necessarium ad salutem requiri nullum. Thomas Hobbes (De cive, 18.3). ${ }^{2}$

Este artículo aborda el problema de la teología política en Thomas Hobbes a partir de una revisión de las partes tercera y cuarta de Leviatán, o la materia, forma y poder de un Estado eclesiástico o civil: "De un Estado Cristiano" y "El reino de las tinieblas". ${ }^{3}$ ¿Por qué tomar como corpus de referencia a Leviatán, un clásico que se estudia en todos los cursos introductorios a la Teoría Política o la Historia del Pensamiento Político Moderno? Y, ¿por qué focalizar la indagación en las secciones tercera y cuarta, que precisamente no se suelen leer en esos cursos? Una buena respuesta a estos dos interrogantes la dio J.G.A Pocock hace más de cuarenta años:

"Leviathan consists of four books, with an introduction and a conclusion. Books I and II contain the doctrine to which attention has already been given (...) and history of philosophy has rightly been focus on them. But at the midpoint in the whole work, at the end of book II and the outset of book III, Hobbes embarks on a new course". ${ }^{4}$

Ahora bien: ¿qué se entiende por teología política en este texto?

Para Carl Schmitt, la teología política es sinónimo de la sociología de los conceptos políticos que permite, en el estudio de la temprana modernidad, asociar una forma política - el Estado- y al sujeto por medio de la concepción de soberanía. El Estado y el sujeto autónomo moderno son la versión secularizada de la potestad divina, voluntad plena, que decide en la excepción: crisis política, existencial o milagro. ${ }^{5}$ Hobbes, gracias a la mediación metafísica de Descartes -señala Schmitt-, pudo hacer del individuo soberano de sí el fundamento de la soberanía política. Sin embargo, esta conjunción abrigaba una paradoja: cuando

2 "Y digo que el cristiano no necesita más artículos de fe que este, como necesarios para salvarse: que Jesús es el Cristo" (Hobbes 1993, 195).

${ }^{3}$ Leviatán fue publicado en inglés en 1651. En la versión latina del libro que data de 1668 se encuentra una reformulación de la interpretación bíblica de Hobbes, particularmente en lo que respecta a la doctrina de la trinidad para responder a las críticas que recibió de sus contemporáneos por su ateísmo (Mintz 1969, 37, 43, 81). En este artículo sólo se hará referencia a la edición inglesa.

${ }^{4}$ Pocock 1989, 159.

${ }^{5}$ Schmitt 2009a, 13, 37, 40, 41, 45-48. 
más soberano de sí era el individuo en la sociedad burguesa, más se rebelaba contra el Estado absolutamente soberano que hacía posible su supervivencia. El Dios artificial creado para calmar el miedo a la muerte violenta fue asesinado por sus hijos, el individualismo y el positivismo liberales. ${ }^{6}$ Todo esto puede ser leído, y así lo hace Carl Schmitt, en las primeras partes de Leviatán de Hobbes. Aunque su interpretación remita a mitos judíos, cristianos y nórdicos para analizar la simbología del leviatán, monstruo bíblico y marino, la mirada schmittiana es bastante secularizada. Quizás consciente de este hecho, años después, Schmitt restituye la trascendencia cuando hace explícito que el edificio auto-regulado de la legalidad moderna se cimienta en el dogma que permitió neutralizar el conflicto, al menos entre cristianos, que asolaba la Europa del siglo XVII: Dios es el Cristo. ${ }^{7}$ Ahora bien, en Schmitt persiste una ambigüedad respecto de la teología política. Por un lado, esta última se sustenta en una metafísica monista -en un sentido "epocal"8 pero también esencialista- que hace posible su conceptualización unitaria de la soberanía. Por el otro, el jurista de Plettenberg afirma en sus textos de juventud como la Teología Política I (1922)- y reafirma en sus trabajos de madurez que la teología política es un método para el estudio científico de los conceptos políticos modernos. De hecho, en su respuesta a las críticas de Erik Peterson, que un tanto tardíamente Schmitt publica en Teología política II. La leyenda de la liquidación de toda teología política (1969), escribe lo siguiente:

"Peterson conocía muy bien mi libro Teología Política de 1922. Sin embargo, este no se refiere a un dogma teológico, sino a un problema teórico científico y de la historia de los conceptos: la estructura e identidad de los conceptos empleados por las argumentaciones y conocimientos teológicos y jurídicos". 9

${ }^{6}$ Schmitt 1997, 74-84, 100-1, 117-21, 141. En el debate acerca de los milagros, Schmitt analiza los capítulos 37 y 42 de la tercera parte de Leviatán, además del 26 de la primera.

${ }^{7}$ Schmitt 2009b, 150-151. El prólogo y las notas a los corolarios, donde figura la cita al "cristal de Hobbes", son de 1963.

${ }^{8}$ La noción de metafísica epocal está tomada del estudio preliminar de Jorge Dotti que precede la edición de Romanticismo político de Carl Schmitt (2000). Allí Dotti (2000, 11) sostiene que "La lectura de la filosofía moderna que propone Schmitt, a grandes trazos, es una confirmación ex ante de su afirmación futura, en el sentido de que la clave para la comprensión de una visión política epocal está en la metafísica que esa época sabe formular”. Para Duso (2015, 183-5) hay al menos cuatro acepciones de la Teología Política en Schmitt: 1. Secularización de conceptos teológicos a políticos; 2. Fundamentación Teológica de la política; 3. Absolutización de la política en clave totalitaria; 4. Identidad de la estructura entre el ámbito teológico y metafísico En este artículo, se opta por una línea hermenéutica que combina la primera y la cuarta. Sobre la amplia bibliografía sobre los sentidos de Teología Política en el campo la Teoría y Filosofía Política italiana, se puede consultar también a Duso $(2015,183$ nota 1$)$.

9 Schmitt 2001, 402-3. "Meine Schrift Politische Theologie aus dem Jahre 1922 war Peterson aus vielen Gesprächen wohlbekannt. Sie trifft aber kein theologische Dogma, sondern ein wissenchaftstheoretisches und begriffsgeschichtliches Problem: die Struktur-Identität der Begriffe theologischer und juristischer Argumentationen und Erkenntnisse" (Schmitt 2008, 189). Para facilitar la comprensión, las citas extensas están transcriptas en castellano en el cuerpo 
Para Erik Peterson, ${ }^{10}$ la teología cristiana es pura o no es nada. Desde un punto de vista doctrinal y lógico, el cristianismo es incompatible con la teología política por el dogma trinitario:

"Lo que nosotros honramos es la monarquía, pero no una monarquía circunscrita a una sola persona -pues es posible que este ser único, encontrándose en discordia consigo mismo, se convierta en múltiplesino una monarquía construida por la misma dignidad de naturaleza, sinfonía de pensamientos, identidad de movimiento y retorno a la unidad de los seres que proceden de ella -lo que es imposible cuando se trata de naturaleza procreada". ${ }^{11}$

Desde un punto de vista histórico, la teología política se asocia con una forma política: la teocracia judía. "El concepto de monarquía del judaísmo alejandrino era en definitiva un concepto político teológico, destinado a fundamentar la superioridad religiosa del pueblo judío y su misión con el paganismo". ${ }^{12}$ Para Peterson, no es la política la que seculariza conceptos teológicos, sino la teología la que se apropia nociones políticas, e incluso metafísicas. Así pasó en los tiempos del judaísmo helenista (siglo I a. C.), cuando Filón hizo de la metafísica aristotélica que gobernaba el mundo el modelo para reinar en los asuntos humanos y con los primeros padres de la Iglesia. La politización de la teología sigue vigente, especialmente en el plano litúrgico, aunque Gregorio Nacianceno y San Agustín pretendieron, con relativo éxito, independizar el reino divino de la política humana. ${ }^{13}$

En síntesis, mientras para Schmitt la teología política implica reconocer la relación conceptual-estructural entre los ámbitos políticos y teológicos, para Peterson teología política supone a la "monarquía judía" como una forma política modélica. ¿Cuál de estas concepciones predomina en la narrativa hobbesiana, o

del texto, con excepción de los epígrafes y en los casos en los cuales no existe una traducción publicada de referencia.

${ }^{10}$ Peterson 1999, 58, 73, 94.

${ }^{11}$ Peterson 1999, 93-94. En alemán: Peterson 1994, 57-58. Para Peterson la teología argumenta sobre el dogma y no toda exégesis bíblica implica este ejercicio. La teología política no formaría parte de la teología sino de la historia del pensamiento político, aunque apele a fuentes bíblicas (Uribarri 1999 19, 37). Cabe preguntarse, sin embargo, si su reconstrucción de la forma política desde la Antigüedad tardía hasta la Inglaterra de su tiempo es puramente teológica o usa la historia de los sistemas políticos para poner en evidencia una representación metafísica de la sociedad.

12 "Der Monarchie-Begriff des Alexandrinischen Judedentums war letzthin ein politischen-theologischer Begriff, dazu bestimmt, die religiöse Überlegenheit des jüdischen Volkes und Seine Sendung an das Heidentum zu begründen“ (Peterson 1994, 34).

${ }^{13}$ Cuando Schmitt le responde a Peterson en Teología Política II, elude la crítica política de su amigo teólogo que lo asocia con teólogos de la Reichtheologie como defensor del régimen nazi y se centra en el tema metodológico. Para más detalles de la polémica ver: Rodríguez R., Morales (2010). 
es el sabio de Malmesbury tan hereje que propone una combinación superadora de ambas?

Este artículo cuenta con tres apartados, además de la introducción. Primero, se reconstruye la historia de los reinos de Dios en la tierra, presentada en las dos últimas partes de Leviatán, dando particular énfasis a las formas de organización del pueblo judío tal y como aparecen en el Antiguo Testamento. ${ }^{14}$ A continuación, se relaciona la interpretación materialista de la Trinidad y de los espíritus (incluido el Santo) que propone Thomas Hobbes con su concepción del soberano civil como suprema autoridad interpretativa. En la conclusión, se retoma la pregunta que atravesó la introducción ¿de qué tipo de teología política se sirve Thomas Hobbes en su exégesis bíblica de las últimas partes de Leviatán?

\section{2. ¿HAY REINOS DIVINOS EN ESTE MUNDO?}

From the difference between the other two kinds of God's word rational and prophetic, there may be attributed to God, a twofold kingdom, natural, and prophetic: natural, wherein he governeth as many of mankind as acknowledge his providence, by the natural dictates of right reason; and prophetic, wherein having chosen out one peculiar nation (the Jews) for his subjects, he governed them, which he gave them by the mouths of his holy prophets. Thomas Hobbes (Leviathan, 31.4). ${ }^{15}$

Este epígrafe pertenece al capítulo 31, el último de la segunda parte de Leviatán. La oración con la que concluye el párrafo afirma que dicho capítulo se ocupa del reino natural de Dios. Por consiguiente, se puede implicar que los siguientes capítulos, sobre todo los de la parte III, se dedican al otro reino, el profético. Sin embargo, este último resulta un reino de este mundo: la nación elegida que Dios gobernó directamente, como lo hará Jesús después del juicio final. Parafraseando a Leo Strauss, se podría decir que Hobbes, en las tercera y cuarta partes de Leviatán, pone entre paréntesis la razón, en su caso, de la ciencia moderna inspirada en la antigua geometría euclidiana, y prioriza la revelación. ${ }^{16} \mathrm{Si}$ bien para el sabio de Malmesbury, la cuna de esta razón no era la Atenas de Aristóteles sino la París de Mersenne y Gassendi, ${ }^{17}$ la revelación sí parece tener su

${ }^{14}$ Ver Assman (2006, 2012), Taub (2017, 54-7) y Oz-Salzberger (2002).

15 Hobbes 1998, 223: "Partiendo de la diferencia entre las otras dos clases de palabra divina, la racional y la profética, podemos atribuir a Dios un doble reino, el natural y el profético: un reino natural en el que gobierna a todos aquellos hombres que reconocen su providencia en los dictados de la razón; y un reino profético en el que, habiendo escogido a un pueblo particular, el pueblo judío, como súbdito suyo, lo gobernó como a ningún otro, no solo por la razón natural, sino también por las leyes positivas que le dio por boca de sus santos profetas. Del reino natural de Dios me propongo hablar en este capítulo" (Hobbes 2002, 302).

${ }^{16}$ Strauss 1967, 49-51.

17 Tönnies 1988, 49-74. 
origen, como para el propio Strauss, en la antigua Jerusalén. Aunque los historiadores intelectuales, sobre todo aquellos que han reconstruido la génesis del republicanismo moderno, hayan ignorado esta fuente, "the story of political Hebraism, the sustained effort to read the Bible politically during the seventeenth century, is one of the most exciting chapters in the history of political thought — and it is a chapter rather than an anecdote". ${ }^{18}$ En ese contexto se comprende la apuesta teológico política de Hobbes.

Según su lectura de la Biblia, el reino profético es, ante todo, una forma política histórica: la monarquía judía. Dios gobernó a los judíos directamente primero -incluso cuando lo hizo a través de Moisés, que para Hobbes es, junto con Jesús, uno de sus representantes terrenos ${ }^{-19}$ e indirectamente, después, por medio de reyes. Estos soberanos fueron ungidos para cumplir la voluntad del pueblo elegido, con el consentimiento pero en contra del deseo de Dios.

"Los jueces fueron sucedidos por los reyes, y así como anteriormente toda autoridad en religión y política residía en el sumo sacerdote, residió ahora en el rey. Pues la soberanía sobre el pueblo, que antes, no solo en virtud del poder divino, sino también a causa del pacto especial hecho por los israelitas, residía en Dios e inmediatamente bajo Él el sumo sacerdote como representante suyo en la tierra, fue ahora rechazada por el pueblo con el consentimiento del mismo Dios (...) Y, en consecuencia, al privar al sumo sacerdote de autoridad real, estaban disponiendo de aquel gobierno peculiar de Dios. Y, sin embargo, Dios consintió en ello diciéndole a Samuel (I Samuel viii.7): Oye la voz del pueblo en cuanto pide, pues no es a ti quien rechazan sino a mí, para que reine sobre ellos". 20

Y este gobierno, aunque su historia se relate en la sección dedicada al Estado eclesiástico, es, según las palabras de Hobbes, un gobierno civil. ${ }^{21}$ A partir de esta afirmación se puede concluir que lo que le ocupa a Hobbes no es la religión en sí misma sino la religión civil. Esta última se define como la apropiación de la religión por la política en beneficio de los fines de esta última. Según Jean-

${ }^{18}$ Oz Salzberger $(2002,89)$. Además de esta referencia al texto Fania Oz Salzberger “Jewish Roots of Westenr Freedom" (2002, 101-105, 126 nota 70) que reconstruye el republicanismo en Holanda e Inglaterra de Cunaeus a Spinoza y Locke pasando por Milton y Harrington y le da particular importancia a la Biblia como un modelo político y jurídico de un Estado independiente, no pueden dejar de mencionarse los trabajos de Christopher Hill (1977, 1991, 1993). Cabe aclarar que esta reposición del contexto intelectual de la lectura bíblica de Hobbes no significa que se adhiera acríticamente a la lectura humanista de Hobbes propuesta por Skinner (Rossello 2012, 264) o que se pretenda transformar al autor de Leviatán en un republicano cívico "disfrazado". De hecho, Hobbes usa referencias bíblicas para definir al Leviatán, no como un hombre magno, sino como un animal (serpiente, cocodrilo, ballena) o una mezcla "monstruosa" de varias especies (Schmitt 1997, 40-1, 55, 57, entre otras; Rosello 2012, 266).

${ }^{19}$ Hobbes 2002, 327, 413.

${ }^{20}$ Hobbes 2002, 318, 401.

${ }^{21}$ Hobbes 2002, 274-75, 346-347. 
Jacques Rousseau, en el capítulo 8 del libro III de El contrato social, existen tres tipos de relación entre la religión y la sociedad: la religión del hombre, versión racionalizada e individualista de la fe evangélica; la del ciudadano, que implica el compromiso con el culto público de los dioses de la comunidad política; y una mixtura entre ambas. Ejemplos de la primera serían el cristianismo primitivo; y de la segunda, el paganismo y los israelitas, aunque estos creyeran en un único Dios. El tercer caso estaría representado por el catolicismo romano y la religión de los lamas. A partir de esta tipología rousseauniana se puede sostener que Hobbes propone un cristianismo "judeizado" o un judaísmo cristianizado, según el énfasis se ponga en el contenido dogmático religioso o en la forma política soberana. Para Rousseau, Hobbes ${ }^{22}$ fracasa en su intento de conciliar política y religión porque se inspira en una forma política anacrónica como la teocracia judía y porque no comprende que el cristianismo se resiste a la religión civil por el poder del clero. ${ }^{23}$

Esta "acusación" de Rousseau contra la religión civil de Hobbes inspira el interrogante ordenador de esta interpretación de la lectura hobbesiana de la Biblia: ¿qué forma política histórica resulta ejemplar para justificar los derechos y deberes que corresponden a los soberanos y a los súbditos cristianos, respectivamente?

En los capítulos 32 y 33 de "De un Estado cristiano" se establece que las Sagradas Escrituras constituyen el cánon de la vida cristiana. Para Hobbes, la prioridad en términos de veracidad del Nuevo Testamento respecto del Antiguo no existe. Incluso los textos apócrifos de este último son calificados como tales muchas veces por la lengua en que están escritos (griego y no hebreo) y no por su contenido. ${ }^{24}$ La cuestión acerca de la autoridad de las Escrituras se reduce al siguiente dilema: ¿son los reyes o las asambleas soberanos absolutos, inmediatamente por debajo de Dios, en los territorios de las comunidades políticas cristianas; o unos y otras están sujetos a la autoridad universal de una Iglesia, bajo el mando de un vicario de Cristo ${ }^{25}$ Para encontrar una respuesta, Hobbes le dedica una consideración particular el Reino de Dios que, tras un interregno dedicado a la materialidad de los espíritus (capítulo 34), comienza en el capítulo 35. Allí se plantean dos argumentos clave. Primero, el reino de Dios no es metafórico ni en el Antiguo ni el Nuevo Testamento, más allá de lo que digan los predicadores en los sermones. Segundo, el reino de Dios es la forma política (alianza) constituida de manera particular por Dios y el pueblo de Israel:

${ }^{22}$ Rousseau 2004, 92-93.

${ }^{23}$ Hobbes realiza un consistente ataque al clero (católico y protestante, y en particular dirigido hacia los obispos) que, aunque enfatice en los vicios católicos, no excluye a los protestantes ni tampoco a los sacerdotes judíos. Por ello es factible afirmar que un elemento constante de la religión civil de Hobbes es su anticlericalismo (Hobbes 2002, 463-64, 566-67).

${ }^{24}$ Hobbes 2002, 257, 330

${ }^{25}$ Hobbes 2002, 260, 330. 
"Muy por el contrario, encuentro que Reino de Dios, en la mayoría de los pasajes de la Escritura, significa un reino propiamente así llamado, constituido por los votos del pueblo de Israel de un modo peculiar, en el que escogieron a Dios como su rey en virtud de una alianza hecha con Él cuando Dios les prometió la tierra de Canáan". ${ }^{26}$

"Todas las naciones son mías; pero no es que vosotros seáis míos por eso, sino que lo sois de una manera especial; pues todos los pueblos son míos a causa de mi poder, pero vosotros lo seréis por vuestro propio consentimiento, mediante un pacto, lo cual es un título más que se añada al que poseo sobre todas las naciones". ${ }^{27}$

Este reino de Dios está regulado por la ley positiva (las leyes mosaicas), y quedó interrumpido cuando los judíos eligieron a Saúl como rey, y será restaurado cuando Cristo venga en su majestad a juzgar al mundo. Si así no fuese, y el reino de Dios solo fuera una metáfora de la vida ultraterrena, ¿por qué hay tantas disputas jurisdiccionales entre reyes y sacerdotes aquí y ahora? Hay que señalar, no obstante, que Hobbes presenta la misma ambigüedad de la que acusa a otros cuando se refiere al reino de Cristo, e incluso hace referencia a la máxima: su reino no es de este mundo. ${ }^{28}$ Ahora bien, si se sigue el mismo método que Hobbes aplica a la Biblia y no se pretende a partir de un átomo deducir la materia total de un cuerpo sino componer a esta última a partir de una unificación coherente de los fragmentos, se puede resolver esta supuesta incoherencia. En su primera venida, Jesús ejerció una función pastoral o sacerdotal, predicó, enseñó y aconsejó, sin esperar obediencia alguna más que en los corazones humanos. En su segunda venida reinará y gobernará sobre el mundo todo como lo hizo Dios sobre los judíos antes de que tuvieran reyes.

Tras dos capítulos dedicados a los milagros y a la salvación (37 y 38), se responde al interrogante planteado en el capítulo 35: "No hay sobre la faz de la tierra, una Iglesia Universal a la que todos los cristianos deban obediencia (...) Por lo tanto, no hay más gobierno en esta vida, ni Estado, ni religión, que los temporales". ${ }^{29}$ En el capítulo 40, reaparece la historia de la relación entre Dios y el pueblo judío. ${ }^{30}$ Allí se presenta una síntesis de lo sucedido desde la primera alianza con Abraham hasta la decisión de los hebreos de tener un rey como las otras naciones. Con esta determinación, los hebreos modifican su relación singular con Dios pero no pierden totalmente este vínculo que los distingue porque la

${ }^{26}$ Hobbes 2002, 271, 343.

${ }^{27}$ Hobbes 2002, 274, 345

${ }^{28}$ Hobbes 2002, 322, 342, 406, 428-29.

${ }^{29}$ Hobbes 2002, 312, 392.

${ }^{30}$ Cabe aclarar que este pedido no ocurre nunca en el Pentateuco que es el texto revelado, en los 5 libros de Moisés o la Torá, y menos aún directamente luego de Abraham que pertenece al libro de Génesis, sino que ocurre en otra parte del Antiguo Testamento que son los escritos de los Profetas. 
alianza sigue vigente. Lo que sí sucede es que el gobierno directo de la divinidad sobre este reino tan real como profético deja de ser tal. ${ }^{31}$ Cuando llega el Mesías, o más precisamente el Mesías de los cristianos y del propio Hobbes porque según la tradición judía este aún no ha llegado, no hay más reino ni gobierno, divino o humano, que administre los negocios del pueblo elegido. Aunque Jesús fue "el rey de los judíos", así lo denomina burlonamente Poncio Pilato, ${ }^{32}$ no cuestiona las leyes positivas de los soberanos paganos. ${ }^{33}$ Lo que hizo posible que la ley canónica fuera tal fue la existencia de un poder civil, como lo demuestran los casos de Moisés y Josué. Si fue así en los tiempos del reino profético de Dios, ${ }^{34}$ ¿por qué va ser diferente en los Estados cristianos durante el interregno entre las dos venidas de Jesús al mundo?

En síntesis, a lo largo de la última mitad de Leviatán se narra la historia del Reino de Dios.

En un primer momento, este último coincide con la historia de Israel hasta la llegada de Cristo. Este momento tiene, cuanto menos, dos etapas: el reino de Dios sin reyes y el reino divino a través de ellos. A simple vista, parece que una teocracia es sucedida por otra, sin embargo, no resulta necesariamente así. Con Abraham primero y con Moisés después, aparece una institución fundamental: el pacto. ${ }^{35}$ Ahora bien, la alianza de Dios con los hombres a través de Abraham, que decide por ellos y los gobierna en su carácter de padre de familia, y el convenio renovado con Moisés no son iguales. El príncipe-profeta no representa a ninguna dinastía histórica: su legitimidad se funda en el consentimiento. Así pues, en el medio de la historia teocrática judía, nos encontramos con que el fundamento de la legitimidad del orden político no recae ni en el patrimonialismo ni en las habilidades proféticas del gobernante, sino en la voluntad del pueblo elegido que elige, y hace coincidir su voluntad con el designio de Dios. Así pues, es factible preguntarse: ¿cuándo fue Israel una teocracia? Para Hobbes, y en esto se distingue tanto de Rousseau como de Peterson, la teocracia no es sinónimo de la monarquía judía histórica (que empieza con Saúl y termina en el cautiverio babilónico), sino del gobierno directo de Dios sobre su pueblo, que pone como representante o vicario en la Tierra al sumo sacerdote. Esto sucedió entre judíos desde

${ }^{31}$ Hobbes 2002, 312, 314, 316-17, 320-21, 396, 397, 399-400, 404.

${ }^{32}$ Hobbes 2002, 324, 408. Según Hobbes, Pilatos crucifica a Jesús para satisfacer a los judíos (lo que habría hecho no constituye una falta, según el funcionario romano) y lo condena, no por haber pretendido ser el rey de los judíos, sino por serlo.

${ }^{33}$ Hobbes 2002, 322, 406.

${ }^{34}$ Hobbes 2002, 346, 348, 433, 435.

${ }^{35} \mathrm{Schmitt}$ desestima la importancia del contrato en la teoría de la soberanía presentada en Leviatán. Sin embargo, el pacto o alianza del pueblo judío con Dios, en especial en su versión mosaica, tiene la forma de esta figura jurídica que legitima el orden político. Si bien Schmitt menciona la diferencia entre el contrato individualista hobbesiano y los pactos medievales, no hace mención a este convenio teológico político particular (Schmitt 1997, 76-7). 
la muerte de Moisés hasta la coronación de un rey, y fue una época de caos, porque el liderazgo espiritual subordinó al poder político.

En un segundo momento, el reino de Dios deja de ser exclusivamente el de los judíos cuando arriba el Mesías, combinación de profeta y príncipe. Cristo reina pero no gobierna el mundo y se limita, respetando a las autoridades, a anunciar su segundo reino, efectivamente real. Esta época también tiene dos tiempos: el anterior y el posterior a la conversión cristiana de los reyes paganos que empieza con Constantino. ${ }^{36}$

En un tercer momento, tras las sucesivas crisis y cismas de la cristiandad, una nación, la inglesa, parece distinguirse del resto, pero su gobierno no logra estar a la altura del pueblo elegido por Dios. En esta instancia, Thomas Hobbes interviene para hacer compatibles las instituciones políticas con el destino manifiesto de un pueblo, el suyo propio, el inglés. Por ello, establece paralelismos entre la Inglaterra de su tiempo y la historia del pueblo judío, para que su nación aparezca como igual de heroica que aquel pueblo antiguo. Y entre las hazañas de los ingleses en tiempos recientes Hobbes destaca tres: el haber terminado con el uso de la excomunión como una forma de castigo político, producto de la irreverencia de Enrique VIII; el haber disuelto el nudo que los ataba al poder político a la autoridad papal, un logro de Isabel I; y el haber socavado el predominio de los obispos, gracias al triunfo de los independientes con Oliver Cromwell a la cabeza, por sobre los presbiterianos. ${ }^{37}$

En la última etapa, cuando termine el tiempo que resta, después del juicio, llegará Cristo de nuevo para ahora ejercer directamente su dominio natural, profético y real sobre el mundo. Si tenemos en cuenta que el reino de Dios en su etapa judía tiene al menos dos momentos, en total tendría cinco etapas. Así pues, aunque racionalizada, la escatología hobbesiana coincide, sino en contenido, en forma, con la de los milenaristas defensores de la quinta monarquía: son cinco los reinos de Dios, pasados, presente y futuros, en este mundo.

Al principio de este apartado, se afirmó que en la parte III de Leviatán, y en cierta medida en la IV, se narran los vaivenes en la relación entre política y religión, a partir del ejemplo de la nación judía. El relato hobbesiano no es neutral sino que está políticamente sesgado para poder establecer una analogía entre el destino del pueblo elegido por Dios en la Antigüedad y la nación inglesa que se pretende su encarnación moderna. Podría decirse que Hobbes prioriza la revelación por sobre la razón, al tomar a las Sagradas Escrituras como fuente. Sin embargo, en su relato histórico de cómo en Inglaterra se fueron desatando los nudos que había que romper, para terminar con el dominio papal primero y por último con el episcopal, recurre al método deductivo compositivo. Parece que no habría

\footnotetext{
${ }^{36}$ Hobbes 2002, 327, 413.

${ }^{37}$ Beiner 2011, 70.
} 
tal ruptura entre razón y revelación en Leviatán, sino un uso alternado de ellas, según la necesidad del argumento. ¿Puede ser este último calificado de prudente, es decir, estar basado en la experiencia? Aun a riesgo de contradecir la opinión de Hobbes, ${ }^{38}$ podríamos afirmar que sí: en la materia contingente que constituyen la política y su historia es difícil renunciar a esta forma de juicio en circunstancia. Por ello, sin ser un pensador político historicista, Hobbes, en su interpretación de la forma política en su devenir histórico, parecería admitir que la historia también es la materia de un mundo demasiado humano. Este es el mundo que los seres humanos, con sus cuerpos y pasiones animales, construyen y destruyen mientras creen, equivocadamente tal vez, que son los instrumentos privilegiados a través de los cuales lo divino comunica sus designios. ${ }^{39}$

\section{ENTRE ESPÍRITUS, DEMONIOS Y FIGURAS REPRESENTATIVAS: ¿QUIÉN ES EL SOBERANO INTÉRPRETE DE LAS PALABRAS BÍBLICAS?}

[...] And therefore God, who has been represented (that is personated) thrice, may properly enough be said to be three persons; though neither the word Person nor Trinity, be ascribed to him in the Bible. Lev. 42.3. ${ }^{40}$

Mientras nos relata la historia político-religiosa de la nación judía antigua, Hobbes aplica su razón natural para comprender los pasajes bíblicos que introducen misterios (espíritus, ángeles, demonios, milagros, etc.) que parecerían contradecir su materialismo. ${ }^{41}$ En los capítulos 34 y 36 de Leviatán, se las ingenia para encontrar en las Sagradas Escrituras afirmaciones compatibles con sus creencias de que en el universo todo es corpóreo y que no habría sustancias sin cuerpo. ${ }^{42}$ Sin embargo, hay un uso bíblico, que no es ni metafórico ni propio del lenguaje corriente, que resulta problemático: "Dios es un espíritu". ${ }^{43} \mathrm{Si}$ bien esta proposición desafía nuestro entendimiento porque no podemos conocer la naturaleza de Dios, no solo debe de ser respetada sino que puede ser racionalizada a

${ }^{38}$ Hobbes 2002, 442, 541. Hobbes sostiene que la filosofía no puede basarse en la experiencia, por eso no tiene nada que ver con la prudencia.

${ }^{39}$ Sobre la cuestión de la superación del paradigma humanista para comprender la autoridad política en Hobbes, desde Hobbes y más allá de Hobbes, ver Rosello (2012, 255, 259-61, 265,271 ). La complejidad del tema, especialmente en lo que respecta a los límites del republicanismo, tanto en el contexto específico de producción de Leviatán como en la actualidad, exige un tratamiento extenso y específico que no podrá darse en este artículo.

${ }^{40}$ Hobbes 1998, 328. "Dios, que ha sido representado o personificado de tres modos, puede decirse que es propiamente tres personas, aunque ni la palabra Persona, ni la palabra Trinidad se le atribuyan en la Biblia" (Hobbes 2002, 414).

${ }^{41}$ Para Tönnies $(1988,154)$ ni Hobbes ni Descartes eran materialistas absolutos. Sí lo eran por su oposición al formalismo, y en el caso específico de Hobbes su interés por destruir las creencias supersticiosas (Tönnies 1988, 158), pero no en el sentido radical que adopta el materialismo a partir de los siglos XVIII y XIX.

${ }^{42}$ Hobbes 2002, 260, 331.

${ }^{43}$ Hobbes 2002, 263, 333. 
partir de un análisis lingüístico adecuado. ${ }^{44}$ Sostener que Dios es Espíritu o hablar del Espíritu de Dios no quiere decir otra cosa que Dios es Dios. Por ende, Hobbes puede concluir que, cuando se habla de sustancias incorpóreas en la Biblia, "no es una cosa imaginada, sino real, a saber una sutil sustancia invisible pero que tiene las mismas dimensiones que se dan en los cuerpos más sólidos". ${ }^{45}$

Esta consideración se aplica también a los ángeles y demonios. Los primeros, portadores de mensajes divinos, o son el producto de nuestra imaginación - como se deduce de la lectura hobbesiana del Antiguo Testamento- o son cuerpos sutiles, como parecieran presentarse en el Nuevo. ${ }^{46}$ Los demonios, por su parte, son una mala herencia pagana. Su origen no es otro que un conocimiento poco adecuado de las facultades de la imaginación o de la memoria. Cuando Salvador se dirigía al diablo y le ordenaba someterse al poder de la palabra de Dios, obraba de la misma manera que cuando ordenaba a las enfermedades abandonar un cuerpo, o al viento o al mar someterse a su mandato. Por ello, no hizo uso de un lenguaje impropio. Sin embargo, este acto no desmiente el hecho de que Hobbes no ha “(...) descubierto aun ningún pasaje de la escritura del que pueda deducirse que un hombre estuviese poseído por espíritu corpóreo, excepto el suyo propio mediante el cual todo cuerpo es movido de manera natural". ${ }^{47}$ Así pues, no hay genio maligno que nos haga dudar de todo lo que no sea nuestra capacidad de pensar, ni nada en una mente distinguible del cuerpo. En este punto, Hobbes se separa claramente del dualismo cartesiano, ${ }^{48}$ lo cual impacta no solamente en su ontología sino en su metafísica política.

¿Cómo se entiende, según la hermenéutica hobbesiana, al espíritu en la Biblia? Se trata del poder de Dios que actúa por causas que nos son desconocidas. ${ }^{49}$ Ahora bien, si los espíritus pueden ser fácilmente exorcizados al develar su carácter fantástico o su materialidad, ¿qué pasa con el Espíritu Santo? En un pasaje en el que discute por qué, a pesar de estar escritos por distintos autores, los libros de la Biblia están imbuidos por el mismo espíritu, Hobbes se refiere a la conservación de los derechos del reino de Dios, Padre, Hijo e Espíritu Santo. ${ }^{50}$ Sin embargo, en otros casos, esta trinidad canónica es reemplazada por otra:

“Aquí tenemos la persona de Dios, nacida ahora por tercera vez. Pues así como Moisés y los sumos sacerdotes fueron los representantes de Dios en el Antiguo Testamento, y nuestro salvador mismo lo fue en cuanto hombre, mientras anduvo en la tierra, así también el Espíritu

${ }^{44} \mathrm{Al}$ comienzo del capítulo 34 (Hobbes 2002, 260, 331), Hobbes sostiene que el fundamento de lo verdadero está en el significado de las palabras.

${ }^{45}$ Hobbes 2002, 265, 336.

${ }^{46}$ Hobbes 2002, 266-69, 337-40.

${ }^{47}$ Hobbes 2002, 427, 524.

${ }^{48}$ Frost 2016, 179; Mintz 1969, 90.

${ }^{49}$ Hobbes 2002, 270, 342.

${ }^{50}$ Hobbes 2002, 258, 329. 
Santo, es decir los apóstoles y sus sucesores que habían recibido el Espíritu Santo, lo han representado desde entonces. Y, por tanto, Dios ha sido representado o personificado de tres modos diferentes, puede decirse que es tres personas, aunque ni la palabra Persona ni la palabra Trinidad se le atribuyan en la Biblia."51

En esta Trinidad sobre la tierra, la unidad no es el caso, la unidad no es sobre la cosa; pues el espíritu, el agua y la sangre no son la misma sustancia (...). Pero en la Trinidad del Cielo, las personas son personas de uno y el mismo Dios, aunque representadas en tres tiempos y ocasiones diferentes. Para concluir, la doctrina de la Trinidad de lo que puede deducirse directamente de la escritura, es, en sustancia, esta: que el Dios que es siempre uno y el mismo fue la persona representada por Moisés, la persona representada por el Hijo encarnado y la persona representada por los Apóstoles. ${ }^{52}$

Si decir que Dios es espíritu es lo mismo que decir que Dios es Dios o el medio a través del cual él mismo actúa, la identidad divina pasa a ser monolítica. Y si eso es así, en Dios no conviven tres sustancias en una sola, sino que esta última se encarna en diferentes figuras históricas. Hobbes niega que en la Biblia se haga mención a la palabra "Trinidad" e incluso sostiene que habría un uso alegórico de Espíritu Santo para referirse a los apóstoles que habían recibido el espíritu divino. Así, en Leviatán se sustituye la dogmática trinitaria por otra políticamente mucho más representativa y funcional. ${ }^{53}$

Si bien el intento de Hobbes de racionalizar a los espíritus en general y al Espíritu Santo en particular tiene cierta similitud con el gnosticismo, ${ }^{54}$ en Leviatán no reemplaza una tríada (Padre, Hijo, Espíritu Santo) por una díada (Padre, Hijo). La operación hobbesiana implica que el Dios uno tenga, en principio, tres representantes sobre la faz de la tierra, que tuvieron su poder profético, y en el caso de Moisés, también la soberanía política. Es cierto que por momentos Jesús y Moisés parecen hermanados por sus cualidades mesiánicas. ${ }^{55}$ A Hobbes parece interesarle menos el cierre metafísico de la trinidad que encontrar figuras históricamente representativas de Dios en el gobierno de las cosas humanas. Por ello,

\footnotetext{
${ }^{51}$ Hobbes 2002, 328, 414.

52 Hobbes 2002, 329, 415.

${ }^{53}$ En esta operación hobbesiana aparece una dimensión muy bien señalada por Duso respecto de Carl Schmitt $(2015$ 183, 205): la representación como raíz de la teología política.

${ }^{54} \mathrm{El}$ gnosticismo es el intento de algunos primeros cristianos de combinar la filosofía pagana con el cristianismo. Su postulado principal es que se llega a la salvación por el conocimiento introspectivo. Otros de sus principios son: la división entre el espíritu y la materia, cristología; la lectura alegórica de la Biblia; y el establecimiento de jerarquías humanas y divinas. Hobbes se diferencia de los gnósticos porque es materialista y porque rechaza el sincretismo entre aristotelismo y religión. Acerca de la relación de Hobbes con el gnosticismo y el arrianismo en el contexto del debate entre Schmitt y Peterson respecto de la supremacía de la soberanía y el homoousianismo trinitario ver Otonello 2018.

${ }^{55}$ Sobre el mesianismo judío como un problema teológico político: Taub 2017, 56, 59-60.
} 
luego del reino apostólico - que fue una anarquía, como el período que sucedió al dominio mosaico, y al regio, en el caso del pueblo judío-, aparecen los soberanos cristianos, que son a la vez pastores entre los pastores y legisladores positivos. ${ }^{56}$ Los soberanos pueden establecer qué profecía y qué profeta son dignos de respeto y de veneración pública. Es su autoridad pública la que otorga validez a los milagros, y no hay nadie sobre la tierra que pueda infringir castigos superiores a la muerte, porque ni siquiera hay tal cosa como almas eternas. ${ }^{57}$

Además de ser el supremo profeta porque define quiénes son los verdaderos profetas y cuáles son milagros y profecías válidas, el soberano concentra la summa potestas y la summa auctoritas. Por la razón natural, por las facultades que le fueron históricamente concedidas y por la trascendencia de su mandato, la soberanía consiste en juzgar qué doctrinas se advienen con la paz y pueden ser enseñadas sin generar desorden. ${ }^{58}$ Así pues, la interpretación del sentido públicamente admitido de las escrituras es una facultad del soberano civil, que también las hace ley. Y es infalible porque su decisión es inapelable hasta el juicio final, momento en que quien haya mantenido alguna duda en su foro interno, puede apelar a la justicia y la gloria del redentor.

Si gracias a esta prerrogativa soberana se evitan las discordias del aristotelismo, que no solo promueve una ciencia natural errada, sino hace que los hombres juzguen como tiránica toda forma de gobierno diferente al popular ateniense, ${ }^{59}$ ¿por qué Hobbes se adjudica el derecho de escudriñar las Escrituras con su singular exégesis? Pueden mencionarse dos razones que explican esta aparente conducta herética frente a la supremacía interpretativa del soberano. Por un lado, el miedo al soberano no necesariamente paraliza a quienes se encuentran bajo su mando; por el contrario, gracias a los movimientos de la memoria y anticipación que genera esta pasión, los individuos se atreven a actuar por sí mismos. ${ }^{60} \mathrm{Y}$ es por ello que los súbditos del soberano actúan como soberanos de sí mismos. Consciente o no de que esto es una fantasía, Hobbes obra como soberano de sus palabras cuando escribe todas y cada una de las palabras de Leviatán. Por el otro, en el capítulo 34 de dicho texto, Hobbes establece que el fundamento de todo verdadero raciocinio se encuentra en el significado de las palabras. Ahora, este último depende de diferentes actores según el tema del que se trate y el contexto en que se produzca el discurso. Si se trata de una conversación corriente, el soberano es el emisor; si se trata de la Ciencia Natural, el escritor del tratado; y si

${ }^{56}$ Hobbes 2002, 320, 448. Este último es un derecho heredado de los soberanos paganos que, por el hecho de creer en Jesús, los cristianos no perdieron.

${ }^{57}$ Hobbes 2002, 297, 475.

${ }^{58}$ Hobbes 2002, 320, 448.

${ }^{59}$ Hobbes 2002, 453, 554.

${ }^{60}$ Frost habla de la "ilusión" de la agencia autónoma para ser consistente con el determinismo hobbesiano (Frost 2016, 194-196). 
el problema es el sentido de las escrituras, hay que empezar por la Biblia misma. ${ }^{61}$ En Leviatán hay un escritor que razona como quien escribe sobre cosas de este mundo, aunque se ocupe de los misterios de la fe. Entonces hay, incluso en el marco de la supremacía interpretativa del soberano, autoridad del gobierno y la religión civil, libertad para hacer pública una doctrina que según el autor no es sediciosa pero, paradójicamente, puede despertar el cuestionamiento de los fundamentos tradicionales de la autoridad y hasta el espíritu de rebelión en otros corazones. $^{62}$

\section{TEOLOGÍAS POLÍTICAS EN PIE DE GUERRA: LA RESPUESTA TEÓRICO POLÍTICA DE THOMAS HOBBES EN LEVIATÁN}

Aunque Erik Peterson ${ }^{63}$ reniegue de la teología política que se sirve de la interpretación bíblica para pensar problemas políticos, él mismo ofrece análisis de la relación entre la forma política y la religión en el mundo antiguo y temprano medieval compatible con esa práctica más propia de un pensador político que de uno teólogo puro. Como el autor de El monoteísmo como problema político, Thomas Hobbes encuentra una forma teológico-política en el reino y gobierno del pueblo judío según el Antiguo Testamento. Sin embargo, para el sabio de Malmesbury, la monarquía judía a la que se refiere Peterson con el ejemplo de Filón de Alejandría corresponde a un período específico del reino de Dios en la Tierra, por eso no es la forma más acabada de la teocracia. Y tampoco es el modelo que a Hobbes inspira para pensar la formación y funcionamiento de un cuerpo político. Entonces, si en un principio parecía que la teología política que Peterson, malgré soi, pone en práctica en El monoteísmo como problema político era compatible con la concepción de la soberanía civil y eclesiástica que postula Hobbes, la historia de los reinos de Dios en este mundo que se presenta en el opus magnum hobbesiano y en la cual el pacto, el consentimiento y la representación resultan elementos centrales de la legitimidad política desmiente dicha asimilación.

La hermenéutica textualista de las dos últimas partes de Leviatán presentada en los apartados precedentes cuestiona algunos de los tópicos centrales de la interpretación schmittiana de Hobbes como la dependencia mutua entre la soberanía hobbesiana y el cogito cartesiano, o la irrelevancia política, teórica e histórica del contrato como fundamento jurídico político del Estado moderno. ¿Significa esto que la lectura que hace Carl Schmitt de Leviatán es absolutamente errada? Al menos en lo que respecta a la aceptación de la teología política como una herramienta heurística de la sociología de los conceptos que permite establecer analogías estructurales entre la teología y la política en un momento histórico

\footnotetext{
${ }^{61}$ Hobbes 2002, 260, 331.

${ }^{62}$ Fernández Peychaux 2013, 149-70.

${ }^{63}$ Uribarri 1999, 37.
} 
determinado, Schmitt no estaba tan equivocado. Sin embargo, ¿es esta la única acepción de la teología política, entendida como herramienta heurística, la que está presente en Leviatán de Hobbes? ¿O más allá del método, hacer teología política implica una apuesta metafísica por la fundamentación teológica de la política?

Quienes adoptan una lectura materialista como Diego Fernández Peychaux ${ }^{64}$ no aceptan que se pueda pensar desde Hobbes una metafísica. Desde este punto de vista, la teología política en un sentido fuerte, no como método sino como fundamento último de lo político, no sería un problema hobbesiano. Contrariamente, Giuseppe Duso ${ }^{65}$ insiste en reintroducir una metafísica política en su interpretación de la representación y la soberanía modernas pero termina optando por una interpretación formalista para resolver la tensión entre trascendencia e inmanencia. Sin embargo, una y otra interpretación optan por un Hobbes sin fisuras, sin tensiones, que en última instancia termina justificando, por sus hallazgos - la ciudadanía de los cuerpos en el caso de Peychaux-o sus defectos -la soberanía autónoma y monista para Duso- el modo en que ambos comentaristas analizan la política contemporánea. Aun con objetivos muy diferentes a los de este artículo, la interpretación de Diego Rosello ${ }^{66}$ de la relación entre la melancolía y el concepto moderno de soberanía abre un camino alternativo cuando cuestiona, en Hobbes, con Hobbes y a través de Hobbes, la existencia de una frontera inexpugnable entre lo humano y lo animal. De hecho, quienes a través del lenguaje y la decisión de suscribir pactos parecen alejarse del reino animal para entrar al orden político siguen siendo, sino en todo, en parte, animales. Los cuerpos de los individuos y los cuerpos políticos que aquellos conformaron son comparados con figuras míticas que permiten la convivencia en un mismo ser de rasgos humanos y no humanos. ${ }^{67}$ Incluso la conducta de los hombres no se distingue nítidamente del actuar animal. ${ }^{68} \mathrm{Si}$ los republicanos, que, según los historiadores intelectuales del humanismo cívico, son la quintaesencia de la humanidad misma, pueden ser descriptos en el capítulo 29 de Leviatán como perros rabiosos ("mad dog") que, en lugar de ladrarle a la luna, socaban la soberanía del monarca porque mientras lo atacan por omnipotente su mordedura lo vuelve cada vez más débil, ${ }^{69}$ ¿por qué no es posible un Hobbes que piense la forma política

${ }^{64}$ Fernández Pecyhaux 2018, 2, 9, 10, 19-21.

${ }^{65}$ Duso 2015, 34, 90-1, 250-1.

${ }^{66}$ Rosello 2012, 257, 274.

${ }^{67}$ Rosello 2012, 267-8.

${ }^{68}$ Rosello 2012, 260.

${ }^{69}$ Hobbes (1991, 217, 2002, 278). La traducción textual es: "En suma, no puedo imaginar qué puede ser más perjudicial para una monarquía, que permitir que esos libros sean leídos por el público sin someterlos primero a correcciones hechas por maestros discretos, con el fin de purgarlos del veneno que contienen; veneno que, sin dudarlo, me atrevo a comparar con la mordedura de un perro rabioso, que produce una enfermedad que los médicos llaman hidrofobia, o miedo al agua. Pues así como el que padece tal mordedura está continuamente atormentado por la sed y, sin embargo, aborrece el agua y se encuentra en un estado tal que parece como si el 
en el límite, difuso, borroso, y siempre solapado, entre lo material y lo espiritual, lo animal y humano, lo secular y lo teológico ${ }^{70}$ Tal vez no sea en cada uno de los pares de esta díada, sino en su articulación tensionada donde se juegue el sentido de la política.

La interpretación de las dos últimas partes de Leviatán de este artículo coincide con Duso en la importancia de la representación en el constructo teórico hobbesiano pero no tanto por sus proyecciones hacia la política moderna sino porque este concepto también puede ser usado para pensar políticamente un problema teológico: el dogma trinitario. También interesa rescatar un Hobbes que, más allá de la búsqueda de principios cuya validez sea universal ${ }^{71}$ no descarta los casos históricos a la hora de reflexionar acerca de las formas políticas y cómo estas se adaptan a la contingencia. Entonces, la teología política que se rastreó en el Leviatán es un método para el análisis de los conceptos políticos en sus contextos pero la que se encontró también implica un desafío para pensar cuál es el fundamento de lo político en un mundo como el contemporáneo que reniega tanto de la trascendencia como de la inmanencia.

\footnotetext{
veneno hiciera por convertirlo en un perro, así también cuando una monarquía ha sido mordida en su propia carne por esos escritores demócratas que constantemente ladran contra ese sistema, lo que éste más necesita es un monarca fuerte; mas cuando lo tienen, y por causa de una cierta tiranofobia, o miedo a ser fuertemente gobernados, lo aborrecen".

${ }^{70}$ Según Rosello $(2012,256)$ en los años formativos de Hobbes, la licantropía pasó de ser una figura teológica a un síndrome fisiológico. Desde allí también se puede explorar un vínculo entre la melancolía, forma política y proceso de individuación, tres elementos claramente identificables en el barroco, período estético político con el que puede identificarse el contexto de producción de Hobbes. Para profundizar en la relación entre la melancolía y soberanía en el contexto del barroco, el clásico de Walter Benjamin (1990) es una referencia ineludible

${ }^{71}$ Según Tönnies $(1988,167)$ esto es así porque la causa de lo que sucede sólo es accesible a través de la razón, aunque como consecuencia, la realidad se conozca mediante la experiencia sensible.
} 


\section{BIBLIOGRAFIA}

Abdo Ferez, Cecilia, Fernández Peychaux, Diego, Rodríguez Rial, Gabriela. 2018. Hobbes, el hereje. Teología, política y materialismo. Buenos Aires: EUDEBA.

Assmann, Jan. 2006. La distinción mosaica o el precio del monoteísmo. Madrid: Ediciones Akal.

Assmann, Jan. 2012. "Monoteísmo e iconoclastia como teología política". En Iconoclastia. La ambivalencia de la mirada, editado por Carlos A. Otero, 99-122. Madrid: La Oficina de Arte y Ediciones.

Beiner, Ronald. 2011. Civil religion. A dialogue in the history of political philosophy. Nueva York: Cambridge University Press.

Benjamin, Walter. 1990. El origen del drama barroco alemán. Madrid: Taurus Humanidades.

Dotti, Jorge. 2000. “Definidme como queráis, pero no como romántico"”. En Romanticismo político, de Carl Schmitt, 9-39. Bernal: UNQUI.

Dotti, Jorge. 2000. "Romanticismo o decisión política: aut aut". Prismas. Revista de Historia Intelectual $N^{\circ}$ 4: 85-102.

Dotti, Jorge. 2014. "La representación teológico política en Carl Schmitt". Avatares Filosóficos $N^{\circ}$ 1: 27-54.

Fernández Peychaux, Diego Alejandro. 2013. "Thomas Hobbes: liberad, miedo y resistencia política". Ingenium. Revista de Historia del Pensamiento Moderno $N^{\circ}$ 7: 149-170.

Fernández Peychaux, Diego. 2018. "El materialismo de Hobbes. Prolegómenos para una figuración americana de la soberanía" Araucaria. Revista Iberoamericana de Filosofía, Política y Humanidades, año 20, no 39. Primer semestre de 2018, 1-23.

Frost, Samantha. 2016. "El miedo y la ilusión de autonomía". Las Torres de Lucca $N^{\circ}$ 9: 175-200.

Hill, Christopher. 1977. Milton and the English Revolution. Londres: Faber \& Faber.

Hill, Christopher. 1991. The world turned upside down: radical ideas during the English Revolution. Londres: Penguin.

Hill, Christopher. 1993. The English Bible and the seventeenth-century revolution. Londres: Allen Lane.

Hobbes, Thomas. 1993. El ciudadano. Madrid: Debate-CSIC.

Hobbes, Thomas. 1998. Leviathan. Nueva York: Oxford University Press.

Hobbes, Thomas. 2002. Leviatán. La materia, forma y poder de un Estado eclesiástico o civil. Madrid: Alianza.

Mintz, Samuel. 1969. The Hunting of Leviathan. Seventeenth-Century reaction to the materialism and moral philosophy of Thomas Hobbes. Cambridge: Cambridge Universtiy Press. 
Monod, Jean-Claude. 2015. La querella de la secularización. Teología política y filosofías de la historia de Hegel a Blumenberg. Buenos Aires: Amorrortu.

Ottonello, Rodrígo. 2018. "El homoousianismo político religioso de Thomas Hobbes". En Hobbes, el hereje. Teología, política y materialismo, compilado por Cecilia Abdo Férez, Diego Fernández Peychaux y Gabriela Rodríguez Rial, Buenos Aires, EUDEBA.

Oz-Salzberge, Fania. 2002. "The Jewish Roots of Western Freedom”. Azure Vol. 13: 88-132.

Peterson, Erik. 1994. Theologische Traktate, Band 1. Würzburg: Echter Verlag.

Peterson, Erik. 1999. El monoteísmo como problema político. Madrid: Mínima Trotta.

Pocock, John Greville Agard. 1989. "Time, history and eschatology in the thought of Thomas Hobbes". En Politics, language and time. Essays on political thought and history, 148-201. Chicago: The University of Chicago Press.

Rodríguez Rial, Gabriela \& Morales, Pamela. 2010. “Teología y Política: ¿Oposición o antinomia convergente?”. En Entre Antiguos y Modernos. Hermenéutica, ética y política, editado por Óscar Mauricio Donato, 121-143. Bogotá: Universidad Libre, Facultad de Filosofía.

Rossello, Diego 2012. "Hobbes and the Wolf-Man: Melancholy and Animality in Modern Sovereignty". New Literary History, Volume 43, Number 2, Spring, 255-279.

Rousseau, Jean-Jacques. 2004. El contrato social. México: Porrúa.

Schmitt, Carl. 1997. El Leviatán en la teoría del Estado de Thomas Hobbes. México, UAM, Azcapotzalco.

Schmitt, Carl. 2000. Romanticismo político. Bernal: UNQUI.

Schmitt, Carl. 2001. "Teología Política II. La leyenda de la liquidación de toda Teología Política" en Carl Schmitt. Teólogo de la política, compilado por Héctor Orestes Aguilar, 391-460. México: FCE.

Schmitt, Carl. 2008. Politische Theologie II. Die Legende von der Erledigung jeder Politischen Theologie. Berlin: Dunker \& Humblot.

Schmitt, Carl. 2009a. "Teología Política. Cuatro capítulos sobre la doctrina de la soberanía". En Teología política, 9-58. Madrid: Trotta.

Schmitt, Carl. 2009b. El concepto de lo político. Texto de 1932, con un prólogo y tres corolarios. Madrid: Alianza.

Sommerville, Johann. 2000. "Hobbes, Selden, Erastianism and the history of the Jews". En Hobbes and history, editado por G. A. John Rogers \& Thomas Sorell, 160-188. New York: Routledge.

Straus, Leo. 1967. "Jerusalem and Athens. Some introductory reflections". Commentary $N^{\circ} 43:$ 49-41.

Taub, Emmanuel. 2017. "Violencia, religión y mesianismo. Reflexiones desde la filosofía judía". En La pregunta por la violencia, editado por Sergio Tonkonoff, 53-63. Buenos Aires: Pluriverso Ediciones.

Tönnies, Ferdinand. 1998. Hobbes. Vida y doctrina. Madrid: Alianza Editorial. 
Uribarri, Gabino. 1999. "Erik Peterson: teología y escatología”. El monoteísmo como problema político, Erik Peterson, 9-46. Madrid: Mínima Trotta. 